\section{Jean-Claude Boucaut Muriel Umbhauer Jean-François Riou}

\title{
L'induction du mésoderme
}

L'induction du mésoderme est l'un des processus les plus importants parmi ceux qui contribuent à établir le plan d'organisation primaire des embryons de vertébrés. Les concepts qui s'y rattachent sont essentiellement fondés sur les études d'embryologie expérimentale réalisées chez les amphibiens. L'induction du mésoderme dorsal de la jeune gastrula (organisateur de Spemann) résulte de l'action combinée de facteurs de croissance, tels l'activine et le FGF, et de "modificateurs de compétence " tels noggin ou $W n t$. L'activité de l'organisateur de Spemann requiert l'expression de plusieurs gènes à homéoboîte, parmi lesquels goosecoid joue un rôle crucial. L'extension de cette recherche à d'autres vertébrés est à l'ordre du jour, notamment au poisson-zèbre et à la souris, dont l'étude autoriserait une dissection génétique des mécanismes en cause.

J.-C. Boucaut : professeur à l'université Paris VI. M. Umbhauer : stagiaire de recherche. National institute for medical research, Mill Hill, Londres, Grande-Bretagne. J.-F. Riou : chargé de recherche au Cnrs. Biologie moléculaire et cellulaire du développement, URA 1135 Cnrs, Université Pierreet-Marie-Curie, 9, quai Saint-Bernard, 75005

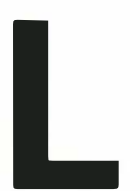

es inductions embryonnaires sont nécessaires au développement des métazoaires. Par définition, elles ont pour conséquence d'engager des cellules embryonnaires dans une voie de différenciation, et cela de manière irréversible. De telles cellules sont qualifiées de déterminées puisque la spécialisation de leurs fonctions est désormais fixée. Les processus inducteurs déterminent les voies de différenciation des cellules embryonnaires.

Dans son principe, toute induction embryonnaire procède d'interactions cellulaires. On distingue des cellules inductrices qui émettent des signaux, et des cellules compétentes capables de les percevoir. En réponse à la perception des signaux inducteurs, les cellules compétentes acquièrent une détermination, elles sont induites. Les signaux inducteurs varient en fonction des axes de pola- rité dorsoventral, et antéropostérieur du futur embryon. Ils participent ainsi à la régionalisation des structures embryonnaires, c'est-à-dire à la réalisation du plan d'organisation propre à chaque métazoaire.

Au cours de la dernière décennie, l'œuf d'amphibien, et en particulier celui du xénope (Xenopus lavis), s'est révélé être un système de choix pour étudier les bases moléculaires et cellulaires de ces mécanismes. Il a permis de faire progresser de manière décisive la connaissance des mécanismes qui sous-tendent l'induction du mésoderme chez les vertébrés.

\section{L'ovocyte de xénope possède un axe de polarité}

Le cytoplasme de l'ovocyte de xénope contient du vitellus. Il est séquestré dans des vésicules membranaires 
qui constituent les plaquettes vitellines. Celles-ci sont de taille variable. Les plus volumineuses sont accumulées dans l'hémisphère qualifié de végétatif. Cet hémisphère n'est pas pigmenté. Son pôle, le pôle végétatif, est opposé au pôle animal. Le noyau de l'ovocyte est situé dans l'hémisphère pigmenté ou hémisphère animal, sous la membrane plasmique, dans le cytoplasme superficiel. Sa position définit le pôle animal.

Sont également mis en réserve dans le cytoplasme de l'ovocyte des protéines et des ARN messagers (ARNm) qui seront utilisés dans les premières phases du développement embryonnaire. Ces constituants sont maternels. La localisation de certains ARNm en des sites spécifiques a été mise en évidence. Melton et al. $(\mathrm{m} / \mathrm{s}$ $n^{\circ} 4$, vol. 4, p. 257) [1] ont identifié un ARNm maternel appelé Vgl qui code pour une protéine proche du facteur transformant TGF $\beta$. D'abord réparti de manière uniforme, l'ARNm Vgl est transloqué lorsque l'ovocyte effectue sa maturation. A ce moment, sa distribution est restreinte à la périphérie du cytoplasme ovocytaire ou cortex, au niveau du pôle végétatif. Le mécanisme de cette translocation implique les microtubules et les microfilaments. Un complexe protéique interagissant avec la région 3 ' non traduite de l'ARNm Vgl et possédant de l'affinité pour l'actine permet l'ancrage au cytosquelette. Un autre ARNm maternel codant pour une protéine sécrétée de la famille wnt (Xwnt-11) présente une distribution similaire à celle de l'ARNm Vgl [2].

$\mathrm{Au}$ total, l'ovocyte de xénope possède un axe de polarité pôle animalpôle végétatif. Il est défini par la position excentrée du noyau, la répartition asymétrique du vitellus et la localisation spécifique de certains ARNm maternels. Chez l'œuf fécondé, le pôle animal préfigure la région antérieure de l'embryon.

\section{La fécondation et la détermination de la polarité dorsoventrale}

Le second axe de polarité est l'axe dorsoventral. Il est établi après la fécondation. Le point d'entrée du spermatozoïde détermine un méridien qui coïncide avec la région ventrale du futur embryon. Le méridien opposé correspond à la future région dorsale.

La fécondation déclenche d'importants remaniements du cytoplasme. Ils constituent la réaction corticale. Celle-ci intervient en phase $G_{2}$ du premier cycle cellulaire, très précisément entre 45 et 90 minutes après la pénétration du spermatozoïde.

En phase $G_{2}$, le cytoplasme de l'œuf qui vient d'être fécondé comprend deux unités structurales: la région superficielle ou cortex d'environ 2 à $5 \mu \mathrm{m}$ d'épaisseur, et la région centrale sous-corticale chargée en plaquettes vitellines. La fécondation entraîne le glissement de ces deux unités structurales l'une par rapport à l'autre : le cortex superficiel effectuant une rotation de $30^{\circ}$, alors que la région centrale sous-corticale reste stable, en équilibre avec la pesanteur $[3,4]$. La réaction corticale se traduit par un déplacement des granules pigmentaires tel que la pigmentation de l'hémisphère animal est moins intense dans la future région dorsale. Au niveau de l'œuf qui est pigmenté en noir, la réaction corticale aboutit à la formation d'un croissant gris dorsal bien visible.

L'irradiation aux rayons ultraviolets (UV) du pôle végétatif de l'œuf fécondé de xénope provoque la déficience complète des structures dorsales [3]. Les remaniements cytoplasmiques de la réaction corticale ne se produisent pas. Il est très vraisemblable que les UV ont pour cible les microtubules du cortex. L'effet des UV dépend du temps d'irradiation. Les doses d'UV les plus fortes entraînent une perte des structures dorsales et antérieures de l'embryon. Un tel embryon «ventralisé » présente une symétrie radiaire.

\section{La transition blastuléenne marque la reprise de la transcription}

La segmentation est celle d'un œuf holoblastique : elle est totale et inégale. Le stade blastula âgée marque la fin de cette étape précoce du développement. A ce stade, les trois tissus embryonnaires, l'ectoderme, le mésoderme et l'endoderme sont déterminés.
Les premiers cycles de division sont courts et égaux. Chez l'œuf de xénope, leur durée est de l'ordre de 35 minutes. Chacun de ces cycles comporte uniquement la phase $\mathrm{S}$ de réplication de l'ADN et la phase $\mathrm{M}$ de mitose. A partir du $12^{\mathrm{e}}$ cycle, se produit un allongement du cycle par l'introduction des phases G1 et G2. La durée du cycle devient inégale et fonction de la position des cellules par rapport à l'axe pôle animal-pôle végétatif. Celles situées dans l'hémisphère animal se divisent plus rapidement. Cette désynchronisation des cycles est qualifiée de transition blastuléenne ou midblastula transition (MBT) [5]. La MBT marque le début de la transcription des gènes de l'œuf fécondé. Entre la fécondation et la MBT, il est admis qu'il n'y a pas de synthèse d'ARN. L'expression génique est pendant toute cette période d'origine maternelle. C'est-à-dire qu'elle dépend des ARN accumulés au cours de l'ovogenèse. L'activation des ARNm maternels permet la traduction des protéines indispensables aux premières étapes du développement. Les nouveaux ARNm transcrits à partir de la MBT représentent les premières expressions des gènes du zygote $[5,6]$.

A l'issue de la segmentation, les trois tissus embryonnaires sont déterminés. Leur mise en place va s'effectuer au cours de la gastrulation et de la neurulation. L'organisation primaire de l'embryon sera achevée à la fin de la neurulation.

\section{Une première approche de l'induction du mésoderme : mise en évidence de signaux inducteurs végétatifs}

Dans la blastula âgée, le mésoderme est disposé à la frontière de l'hémisphère animal et de l'hémisphère végétatif. Il occupe la région moyenne de part et d'autre de l'équateur. Cette région est appelée zone marginale de la blastula. La détermination du mésoderme est acquise au cours de la segmentation. Lorsque les blastomères de la zone marginale sont isolés au stade 32 cellules, et cultivés dans une solution saline, ils se différencient en épiderme. Prélevés plus 


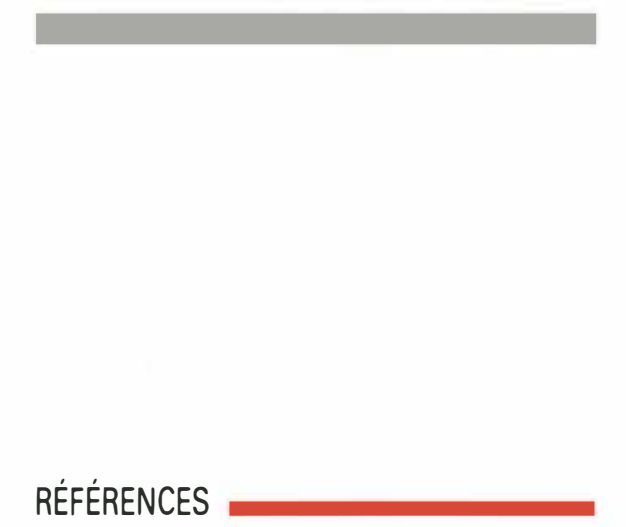

1. Weeks DL, Melton DA. A maternal mRNA localized to the vegetal hemisphere in Xenopus eggs codes for a growth factor related to TGF- $\beta$. Cell $1987 ; 51: 861-7$.

2. Ku M, Melton DA. Xwnt-11: a maternally expressed Xenopus wnt gene. Development $1993 ; 119: 1161-73$.

3. Gerhart J, Danilchik M, Doniach T, Roberts S, Rowming B, Stewart R. Cortical rotation of the Xenopus egg : Consequences for the anteroposterior pattern of the embryonic dorsal development. Development $1989 ; 107: 37-51$.

4. Danilchik MV, Denegre JM. Deep cytoplasmic rearrangements during early development in Xenopus levis. Development $1991 ; 111: 845-56$.

5. Newport J, Kirschner MW. A major developmental transition in early Xenopus embryo: I. Characterization and timing of cellular changes at the midblastula stage. Cell $1982 ; 30: 675-86$.

6. Kimelman D, Kirschner MW, Scherson T. The events of the midblastula transition in Xenopus are regulated by changes in the cell cycle. Cell 1987; $48: 399-407$.

7. Nieuwkoop PD. The formation of mesoderm in Urodelan amphibians. I. Induction by the endoderm. Wilhelm Roux Archiv Entwicklungsmech Org $1969 ; 162$ : 34173.

8. Dale L, Smith JC, Slack JMW. Mesoderm induction in Xenopus lavis: a quantitative study using a cell lineage label and tissuespecific antibodies. J Embryol Exp Morphol $1985 ; 89: 289-312$.

9. Dale L, Slack JMW. Regional specification within the mesoderm of early embryos of Xenopus lavis. Development 1987 ; 100: 27995.

10. Gimlich RL, Gerhart J. Early cellular interactions promote embryonic axis formation in Xenopus levis. Dev Biol 1984 ; $104: 117-30$

11. Gimlich RL. Acquisition of developmental autonomy in the equatorial region of the Xenopus embryo. Dev Biol 1986; 115 : $340-52$.

12. Dale L, Slack JMW. Fate map for the 32 cell stage of Xenopus lcevis. Development 1987 ;

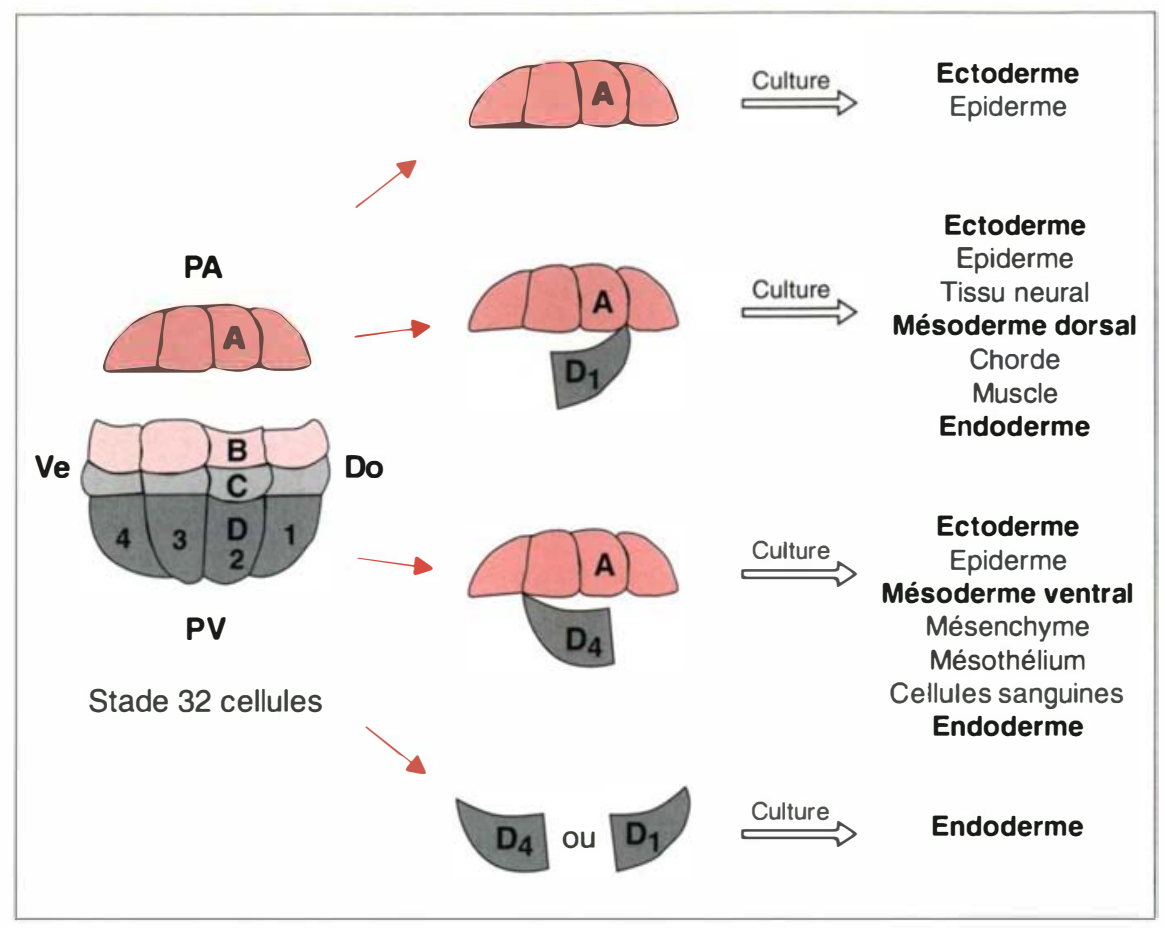

Figure 1. Mise en évidence chez le xénope des signaux inducteurs du mésoderme par la recombinaison de blastomères au stade 32 cellules. $A$ ce stade, l'embryon est constitué de quatre assises $(A, B, C$ et $D)$ de huit blastomères, étagées selon l'axe de polarité pôle animal-pôle végétatif. Les huit blastomères animaux (rangée A) sont isolés et mis en culture seuls ou combinés avec un blastomère végétatif (rangée $D$ ). La rangée $A$ cultivée seule se différencie en épiderme. En combinaison avec le blastomère végétatif dorsal D1, on observe la différenciation de mésoderme dorsal dans l'explant (chorde et muscle). En combinaison avec le blastomère végétatif ventral D4, le mésoderme formé dans l'explant est de type ventral (mésenchyme, mésothélium, cellules sanguines). Les cellules mésodermiques observées dérivent des blastomères de la rangée $A$. Les blastomères D1 et D4 isolés ne forment que de l'endoderme. Ce type d'expérience suggère que deux types de signaux inducteurs sont émis par l'hémisphère végétatif, un signal dorsal et un signal ventral. Do : région dorsale; PA : pôle animal; PV : pôle végétatif ; Ve : région ventrale. (D'après [9].)

tardivement, ils développent en culture du mésoderme. Le rôle des interactions entre les blastomères de l'hémisphère animal et ceux de l'hémisphère végétatif dans l'induction du mésoderme est mis en évidence par des expériences d'association in vitro de ces deux régions au stade jeune blastula. A ce stade, la partie animale ectodermique appelée calotte animale, une fois isolée et mise en culture, se différencie en épiderme. L'hémisphère végétatif isolé et cultivé évolue en endoderme peu différencié. La recombinaison des deux conduit à la formation de différents tissus mésodermiques tels que la chor- de, le muscle et le mésenchyme [7]. L'utilisation de marqueurs a permis d'établir que, dans ces recombinaisons, les tissus mésodermiques différenciés proviennent des cellules de la calotte animale ectodermique [8]

L'association de la calotte ectodermique de la jeune blastula avec, soit la moitié dorsale, soit la moitié ventrale de l'hémisphère végétatif, aboutit à des dérivés mésodermiques différents. La moitié végétative dorsale induit principalement la formation de la chorde et du muscle, tissus normalement localisés dans la région dorsale de l'embryon. La moitié végétative ventrale induit du 


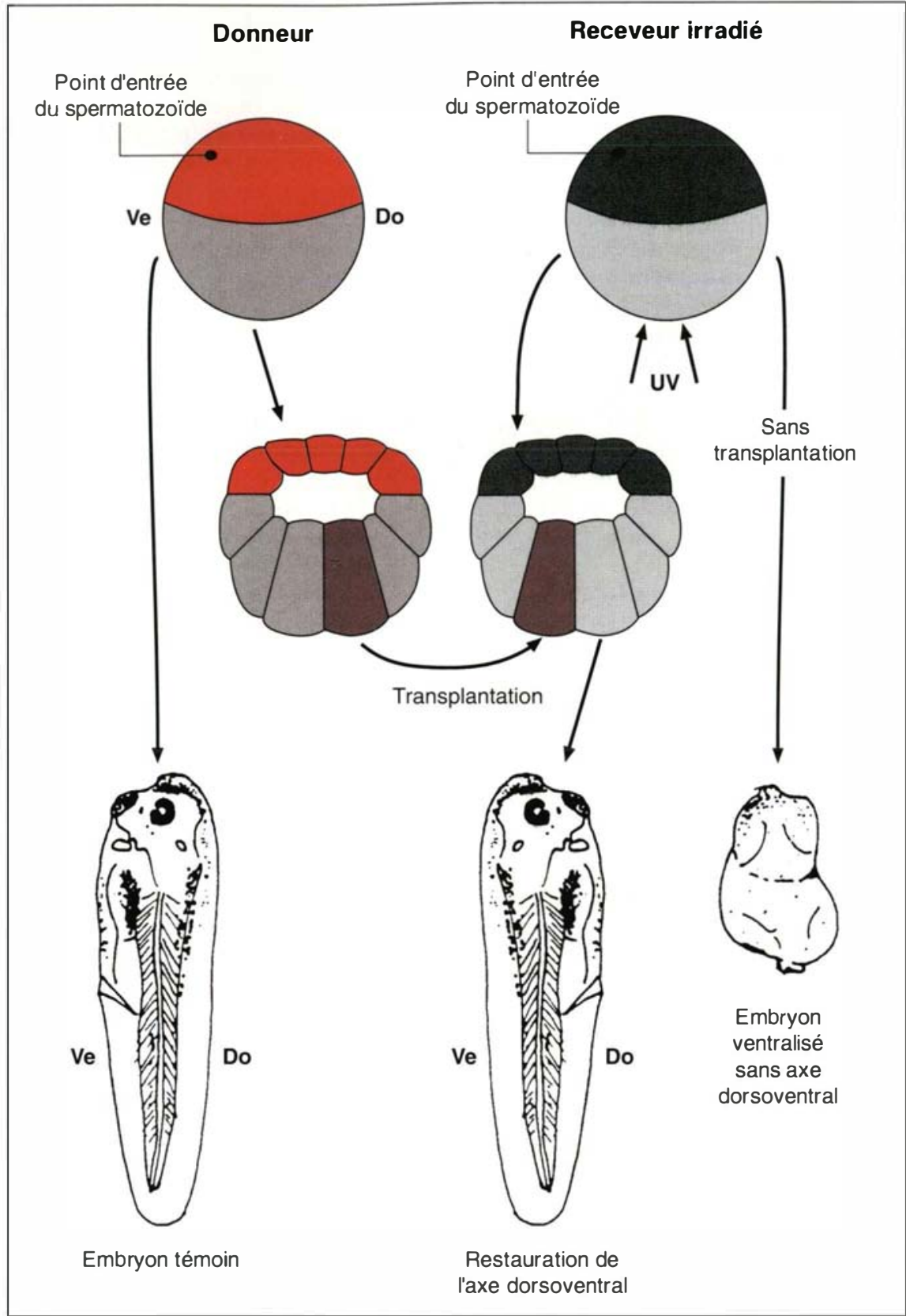

Figure 2. Le centre de Nieuwkoop : mise en évidence par la greffe de blastomères au stade 32 cellules chez le xénope. Un blastomère végétatif dorsal d'un embryon non irradié est greffé à la place d'un blastomère végétatif d'un embryon ayant été irradié aux ultraviolets (UV) au stade indivis. L'irradiation aux UV inhibe l'établissement de la polarité dorsoventrale. Elle entraîne l'absence d'axe embryonnaire. La transplantation du blastomère végétatif dorsal restaure la polarité dorsoventrale. Un axe embryonnaire se met en place au niveau du blastomère transplanté. Les cellules descendant du blastomère végétatif dorsal greffé sont situées uniquement dans l'endoderme de l'embryon. Les structures mésodermiques qui constituent l'axe embryonnaire (chorde, somites) proviennent exclusivement de l'hôte. Ces observations montrent qu'au stade 32 cellules les blastomères végétatifs dorsaux induisent la formation d'un axe embryonnaire sans y participer. Les cellules dérivant de ces blastomères végétatifs dorsaux constituent le centre de Nieuwkoop qui est défini comme étant le lieu d'émission des signaux inducteurs de l'organisateur de Spemann. Do : région dorsale ; Ve : région ventrale. (D'après [10].) $\mathrm{m} / \mathrm{s} n^{\circ} 8 / 9$ vol. 10 , août-septembre 94 mésenchyme, du mésothélium et des cellules ressemblant aux érythrocytes qui constituent des dérivés mésodermiques ventraux [8]. Ces résultats ont été repris par Dale et Slack [9] en recombinant, au stade 32 cellules, les huit blastomères animaux avec un seul des blastomères végétatifs (figure 1). Le blastomère végétatif le plus dorsal induit principalement du mésoderme dorsal ; celui-ci est caractérisé par de la chorde et une grande quantité de muscle (figure 1). Les blastomères végétatifs latéraux et ventraux induisent les cellules animales ectodermiques en mésoderme de caractère ventral. Les explants cultivés comprennent alors très peu de muscle, du mésothélium, du mésenchyme et des cellules sanguines. Ces résultats ont conduit à proposer l'intervention de deux signaux inducteurs issus de l'hémisphère végétatif: l'un émis par les blastomères végétatifs latéraux et ventraux induisant du mésoderme ventral, l'autre provenant des blastomères végétatifs dorsaux induisant du mésoderme dorsal.

\section{Le centre de Nieuwkoop est le lieu d'émission des signaux inducteurs végétatifs dorsaux}

Les blastomères impliqués dans l'émission des signaux inducteurs dorsaux ont été localisés chez l'embryon de xénope aux stades 32 et 64 cellules par des expériences de transplantation. Les blastomères végétatifs prélevés dans la région dorsale et transplantés dans la région ventrale d'un embryon receveur induisent la formation d'un axe embryonnaire secondaire. De même, la greffe des blastomères végétatifs et dorsaux dans un embryon de 64 cellules issu d'un œuf traité par les UV restaure la formation d'un axe embryonnaire [10, 11] (figure 2).

Au stade 64 cellules, la greffe d'un blastomère dorsal et végétatif, marqué par un traceur fluorescent sur un embryon receveur non marqué, induit un axe embryonnaire surnuméraire en position ventrale. Les cellules dérivant du blastomère greffé contribuent uniquement à la formation de l'endoderme et de ses dérivés. Les structures mésodermiques axiales (chorde, somites) induites 


\section{RÉFÉRENCES}

13. Slack JMW, Forman D. An interaction between dorsal and ventral regions of the marginal zone in early amphibian embryos. JEmbryol Exp Morphol 1980 ; 56 : 283-99.

14. Spemann $H$, Mangold $H$. Über Induktion von Embryonalanlagen durch Implantation artfremden Organisatoren. Arch f mikr Anat u EntwMech 1924; 100 : 599 638

15. Condamine $\mathrm{H}$. L'induction mésodermique et la dorsalisation de l'embryon d'amphibien. médecine/sciences $1992 ; 8: 379$ 81 .

16. Slack JMW, Darlington DG, Heath JK, Godsave SF. Mesoderm induction in early Xenopus embryos by heparin-binding growth factors. Nature $1987 ; 326$ : 197-200.

17. Rosa F, Roberts AB, Danielpour D, Dart LL, Sporn MB, Dawid IB. Mesoderm induction in amphibians : the role of TGF$\beta 2$-like factors. Science $1988 ; 239: 783-5$.

18. Slack JMW, Isaacs HV. Presence of basic fibroblast growth factor in the early Xenopus embryo. Development 1989 ; 105 : 147-53.

19. Isaacs HV, Tannahill D, Slack JMW. Expression of a novel FGF in Xenopus embryo. A new candidate inducing factor for mesoderm formation and anteroposterior specification. Development 1992 ; $114: 711-20$.

20. Godsave SF, Shiurba RA. Xenopus blastulae show regional differences in competence for mesoderm induction : correlation with endogenous basic fibroblast growth factor levels. Dev Biol $1992 ; 151$ : 506-15.

21. Musci T, Amaya E, Kirschner MW. Regulation of the fibroblast growth factor receptor in early Xenopus embryos. Proc Natl Acad Sci USA 1990 ; 87 : 8365-9.

22. Friesel R, Brown SAN. Spatially restricted expression of fibroblast growth factor receptor-2 during Xenopus development. Development 1992 ; 116 : 10518.

23. Amaya E, Musci TJ, Kirschner MW. Expression of a dominant negative mutant of the FGF receptor disrupts mesoderm formation in Xenopus embryos. Cell 1991 ; secondairement sont exclusivement édifiées à partir des cellules de l'hôte. Les cellules telles que les blastomères dorsaux et végétatifs du stade 64 cellules, qui induisent un axe embryonnaire en recrutant les cellules de l'hôte, mais sans participer elles-mêmes à cet axe, constituent le centre de Nieuwkoop. A partir du stade 64 cellules, le centre de Nieuwkoop représente le lieu d'émission des signaux inducteurs végétatifs dorsaux. Ces signaux inducteurs sont responsables de la formation du mésoderme dorsal. Chez la jeune gastrula, la zone marginale dorsale comprend les cellules qui donnent les structures mésodermiques les plus dorsales. Elle constitue l'organisateur de Spemann. Le centre de Nieuwkoop est l'inducteur de l'organisateur de Spemann.

\section{L'organisateur de Spemann est impliqué dans la régionalisation du mésoderme}

L'analyse à l'aide de marqueurs cellulaires montre qu'au cours du développement une grande partie du mésoderme somitique dérive des blastomères de la moitié ventrale de la blastula [12]. Or, les blastomères végétatifs latéraux et ventraux n'induisent pratiquement pas de muscle lorsqu'ils sont associés aux blastomères animaux. Ces différences peu vent s'expliquer par l'émission d'un signal provenant de la zone marginale dorsale qui "dorsalise " le mésoderme ventral adjacent. L'existence de ce signal a été déduite d'expé riences de recombinaisons d'explants de zones marginales ventrales et dorsales isolées au stade jeune gastrula. En culture, la zone marginale ventrale se différencie en mésenchyme, mésothélium et cellules sanguines. Lorsqu'elle est recombinée avec la zone marginale dorsale, la zone marginale ventrale donne naissance à d'importantes quantités de muscle (figure 3) [13]

Le processus de "dorsalisation" est illustré par l'expérience fondamentale réalisée en 1924 par Spemann et Mangold [14] (figure 4). La greffe de la zone marginale dorsale d'une jeune gastrula ou organisateur de Spemann, dans la zone marginale ventrale d'une jeune gastrula rece- veuse, aboutit à la formation d'un axe embryonnaire surnuméraire et complet. La majeure partie du mésoderme somitique et la totalité des dérivés du mésoderme latéral et ventral de l'embryon secondaire sont constituées à partir des cellules de l'hôte. On peut interpréter ce résultat en considérant que, pendant la gastrulation, le mésoderme ventral de l'embryon receveur a été «dorsalisé " en mésoderme somitique sous l'influence d'un signal "dorsalisant" émis par l'organisateur de Spemann.

Les données fournies par l'embryologie expérimentale ont permis d'établir la chronologie des processus aboutissant à la mise en place du mésoderme chez le xénope [15]. Elles sont rassemblées dans le modèle des trois signaux (figure 5). Au moment de la fécondation, la rotation corticale active des déterminants dorsaux dans la future région dorsale de l'embryon. Avant la transition blastuléenne, des signaux émis par l'hémisphère végétatif induisent les cellules de la zone équatoriale à former du mésoderme. Dans la région dorsale, les blastomères végétatifs dorsaux du centre de Nieuwkoop émettent un premier signal qui induit le mésoderme dorsal qui constituera l'organisateur de Spemann. Les blastomères végétatifs ventraux et latéraux émettent un second signal qui induit les régions ventrale et latérales de la zone équatoriale en mésoderme ventral. La régionalisation du mésoderme est définitivement établie au cours de la gastrulation par l'action d'un troisième signal "dorsalisant " [16].

\section{Les inducteurs du mésoderme}

La nature moléculaire des signaux inducteurs du mésoderme commence seulement à être élucidée. Une avancée considérable a été réalisée par la mise en évidence de facteurs de croissance induisant du mésoderme in vitro dans la calotte animale ectodermique de la blastula de xénope (figure 6). Ces facteurs de croissance appartiennent aux familles des facteurs de croissance fibroblastiques (FGF) et des facteurs de croissance transformants (TGF $\beta)\left(m / s n^{\circ} 6\right.$, vol. 8 , p. 825). Les membres de la 


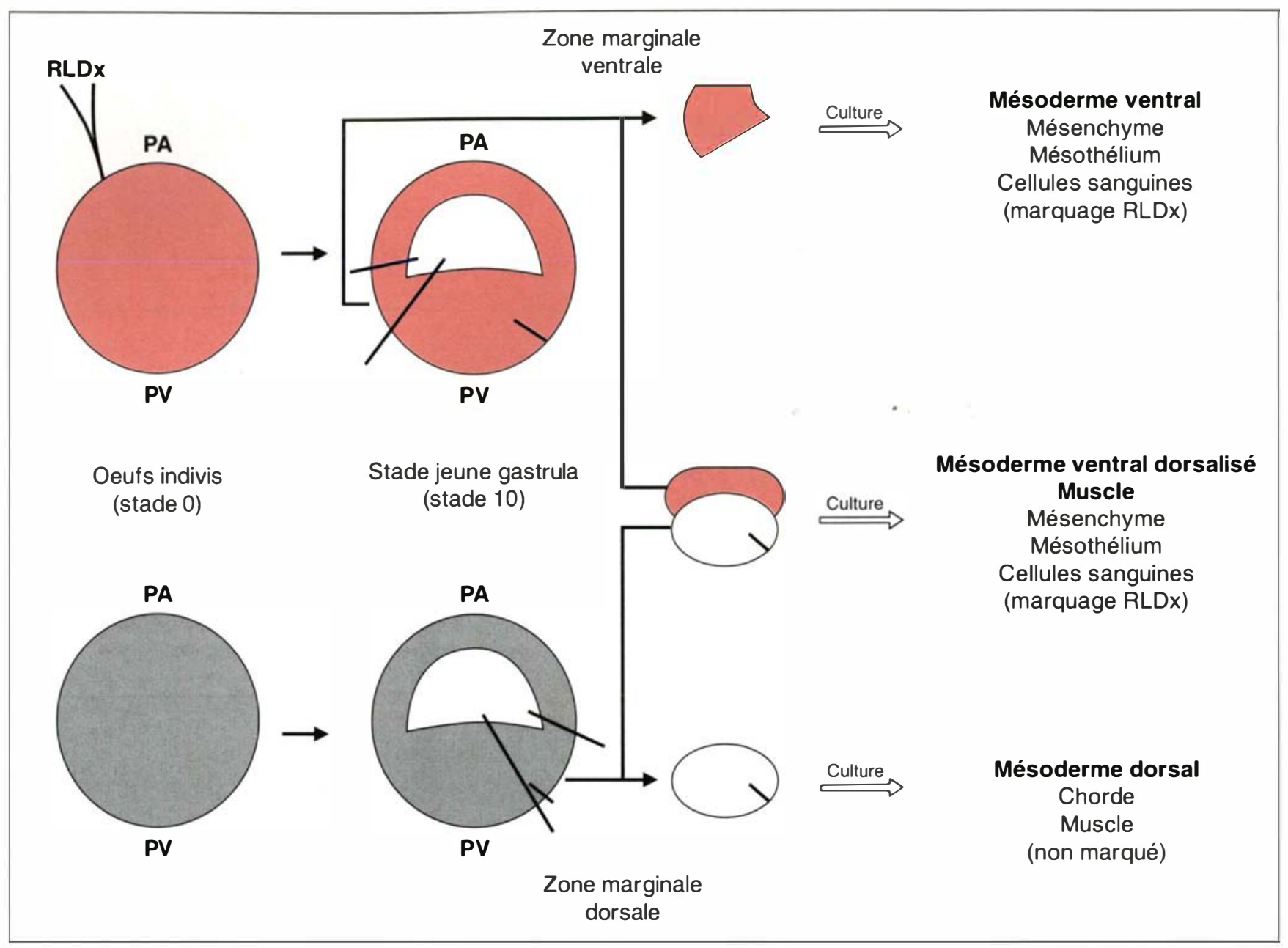

Figure 3. Expérience illustrant l'effet " dorsalisant " de l'organisateur de Spemann. Un œuf de xénope est marqué par l'injection de dextran couplé à la rhodamine (RLDX). Au stade jeune gastrula, la zone marginale ventrale marquée est isolée. Mise en culture, elle donne des dérivés mésodermiques de caractère ventral (mésenchyme, mésothélium, cellules sanguines). Cultivée seule, la zone marginale dorsale (organisateur de Spemann) fournit des dérivés mésodermiques de caractère dorsal (chorde, muscle). Lorsque la zone marginale ventrale marquée est associée à la zone marginale dorsale (organisateur de Spemann) non marquée, elle contribue à la formation de dérivés mésodermiques de caractère plus dorsal. En effet, dans ce type de combinaison, il se développe des formations musculaires qui contiennent des cellules marquées issues de la zone marginale ventrale. Cela suggère l'existence d'un signal émis par l'organisateur de Spemann au cours de la gastrulation, et qui dorsalise le mésoderme ventral précédemment induit. PA : pôle animal ; PV pôle végétatif. (D'après [13].)

famille FGF induisent la différenciation de tissu musculaire, de mésenchyme et de mésothélium [16]. Ceux de la famille TGF $\beta$ induisent du mésoderme dorsal, en particulier la chorde [17]. La diversité des facteurs de croissance capables d'induire du mésoderme in vitro pose la question de l'identité de ceux impliqués dans ce processus au cours de l'embryogenèse. Existe-t-il des fac$\mathrm{m} / \mathrm{s} n^{\circ} 8 / 9$ vol. 10 , août-septembre 94 teurs de croissance dans l'ovocyte et l'embryon d'amphibien? Si oui, qu'en est-il de leurs récepteurs?

Il est actuellement démontré que tous les membres de la famille multigénique FGF, à l'exception de KGF (FGF-7), induisent du mésoderme in vitro. De fait, les $\mathrm{ARNm}$ et/ou les protéines de quatre membres de la famille FGF ont été mis en évidence chez l'embryon de xénope. Trois d'entre eux, le FGF basique (FGFb), le FGF acide (FGFa) et le Xenopus FGF (XeFGF) sont maternels [18, 19]. La protéine FGFb est synthétisée dans l'embryon en quantité suffisante pour induire du mésoderme in vivo. Elle a été localisée avec le FGFa dans les régions végétative et équatoriale de l'œuf en cours de segmentation [20]. Dernièrement, un gène (XeFGF) codant pour un nouveau 


\section{RÉFÉRENCES}

24. Tannahill D, Melton DA. Localized synthesis of the $\mathrm{Vgl}$ protein during early Xenopus development. Development 1989 $106: 775-85$.

25. Thomsen GH, Melton DA. Processed $\mathrm{Vgl}$ protein is an axial mesoderm inducer in Xenopus. Cell 1993 ; 74 : 433-41.

26. Dale L, Matthews G, Colman A. Secretion and mesoderm-inducing activity of the TGF- $\beta$-related domain of Xenopus Vg1. EMBO J1993 ; 12 : 4471-80.

27. Green JBA, Howes G, Symes K, Cooke J, Smith JC. The biological effects of XTCMIF : quantitative comparison with Xenopus bFGF. Development 1990; 108: 173-83.

28. Thomsen GH, Woolf T, Whitman M, Sokol S, Vaughan J, Vale W, Melton DA. Activins are expressed early in Xenopus embryogenesis and can induce axial mesoderm and anterior structures. Cell $1990 ; 63: 485-93$.

29. Asashima $M$, Nakano $H$, Uchiyama $H$ Sugino H, Nakamura T, Eto Y, Ejima D, Nishimatsu $S$, Ueno $N$, Kinoshita $K$. Presence of activin (erythroid differen tiation factor) in unfertilized eggs and blastulae of Xenopus leevis. Proc Natl Acad Sci USA 1991 ; $88: 6511-4$.

30. Rebagliati MR, Dawid IB. Expression of activin transcripts in follicle cells and ovocytes of Xenopus lavis. Dev Biol 1993; ovocytes of
$159: 574-80$.

31. Hemmati-Brivanlou A, Melton DA. A truncated activin receptor inhibits mesoderm induction and formation of axial structures in Xenopus embryos. Nature 1992 ; $359: 609-14$.

32. Green JBA, Smith JC. Graded changes in dose of a Xenopus activin A homologue elicit stepwise transitions in embryonic cel fate. Nature $1990 ; 347: 391-4$.

33. Green JBA, New HV, Smith JC. Response of embryonic Xenopus cells to activin and FGF are separated by multiple dose thresholds and correspond to distinct axes of the mesoderm. Cell $1992 ; 71: 1-20$.

34. Sokol S, Christian JL, Moon RT, Melton DA. Injected Wnt RNA induces complete boby axis in Xenopus embryo. Cell $1991 ; 67: 741-52$.

35. Smith WC, Harland RM. Injected Xwnt-8 RNA acts early in xenopus embryos to promote formation of a vegetal dorsalizing

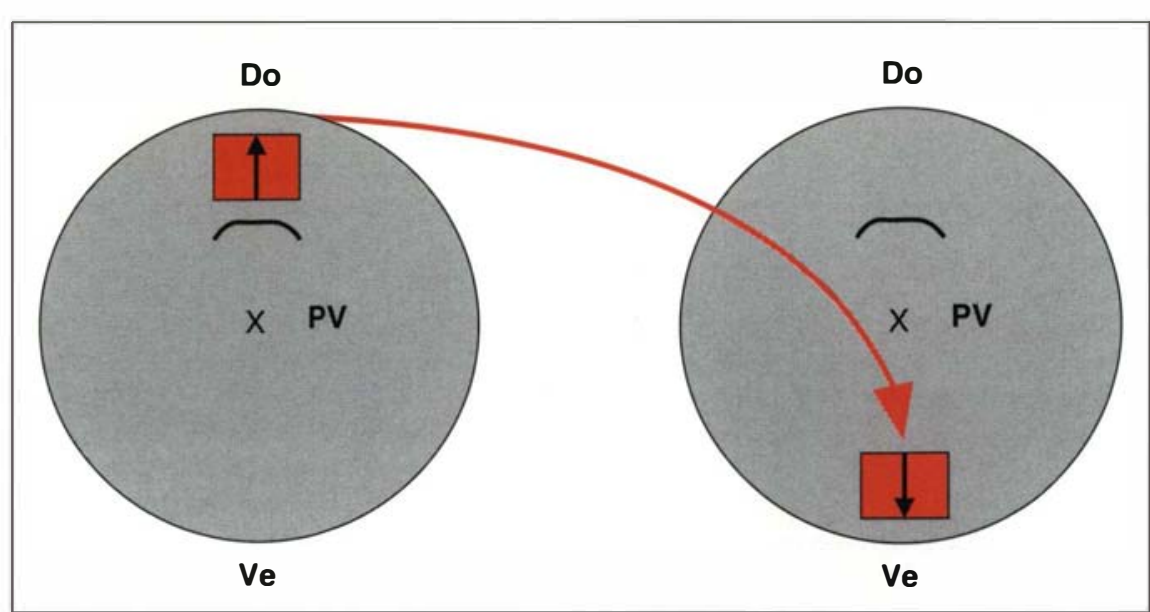

Figure 4. Expérience de Spemann et Mangold (1924). La zone marginale dorsale (organisateur de Spemann) d'une jeune gastrula de xénope est greffée dans la zone marginale ventrale d'un embryon receveur au même stade. II se développe un axe embryonnaire surnuméraire. La plus grande partie des somites de cet axe embryonnaire est formée par les cellules de I'hôte. Cette expérience illustre le processus de "dorsalisation " : la zone marginale dorsale greffée a "dorsalisé " le mésoderme ventral de l'hôte en mésoderme somitique. Do : région dorsale; $P V$ : pôle végétatif; Ve : région ventrale. (D'après [14].)

membre de la famille FGF a été cloné chez le xénope. L'expression des transcrits est maximale au stade gastrula et restreinte à la région postérieure. La protéine possède un peptide signal, 'est sécrétée et présente une activité inductrice du mésoderme en test in vitro [19].

Des récepteurs des FGF ont été clonés chez le xénope $[21,22]$. Les transcrits sont abondants dans la calotte animale et régionalisés au stade gastrula. L'inhibition de la fonction des récepteurs du FGF chez l'embryon de xénope a été réalisée en injectant dans l'œuf fécondé un excès d'ARN exogène codant pour une forme délétée du domaine cytoplasmique à activité tyrosine kinase de ces récepteurs [23]. Les récepteurs mutés sont toujours capables de lier le FGF mais la transduction du signal ne s'effectue pas. Les embryons résultant de cette mutation dominante négative se développent normalement jusqu'au stade neurula. A ce moment et au stade du bourgeon caudal, les structures troncales et caudales sont le plus souvent déficientes. Les somites sont mal organisés. Cette expérience atteste du rôle fonctionnel des FGF et de leurs récepteurs dans les processus de signalisation embryonnai- re. Elle confirme le rôle essentiel des FGF dans l'induction du mésoderme.

Les expériences d'induction du mésoderme in vitro ont permis de révéler le pouvoir inducteur des membres de la famille TGF $\beta$. Il s'agit d'homo- ou d'hétérodimères, synthétisés sous forme de précurseurs, qui sont ensuite amputés de leur région $\mathrm{N}$-terminale et sécrétés. L'ARNm $V g l$, dont on a vu précédemment la localisation restreinte à l'hémisphère végétatif de l'œuf et de la blastula, code pour une protéine de la famille TGF $\beta$. Ces caractéristiques, associées à la mise en évidence de sa capacité à induire du mésoderme, font de Vgl l'un des meilleurs candidats en tant qu'inducteur endogène. Toutefois, les polypeptides produits par l'ARNm Vgl ne paraissent pas mûrs. Ils demeurent séquestrés dans le réticulum endoplasmique à l'état de monomères [24]. Aussi, bien que fortement suggérée, l'implication de $\mathrm{Vgl}$ dans la formation du mésoderme n'est pas à l'heure actuelle formellement établie [25, 26]. Les activines (activine A et activine B), mises en évidence à l'origine à partir de milieux conditionnés par les cellules de la lignée XTC du xénope, sont les inducteurs du mésoderme les 


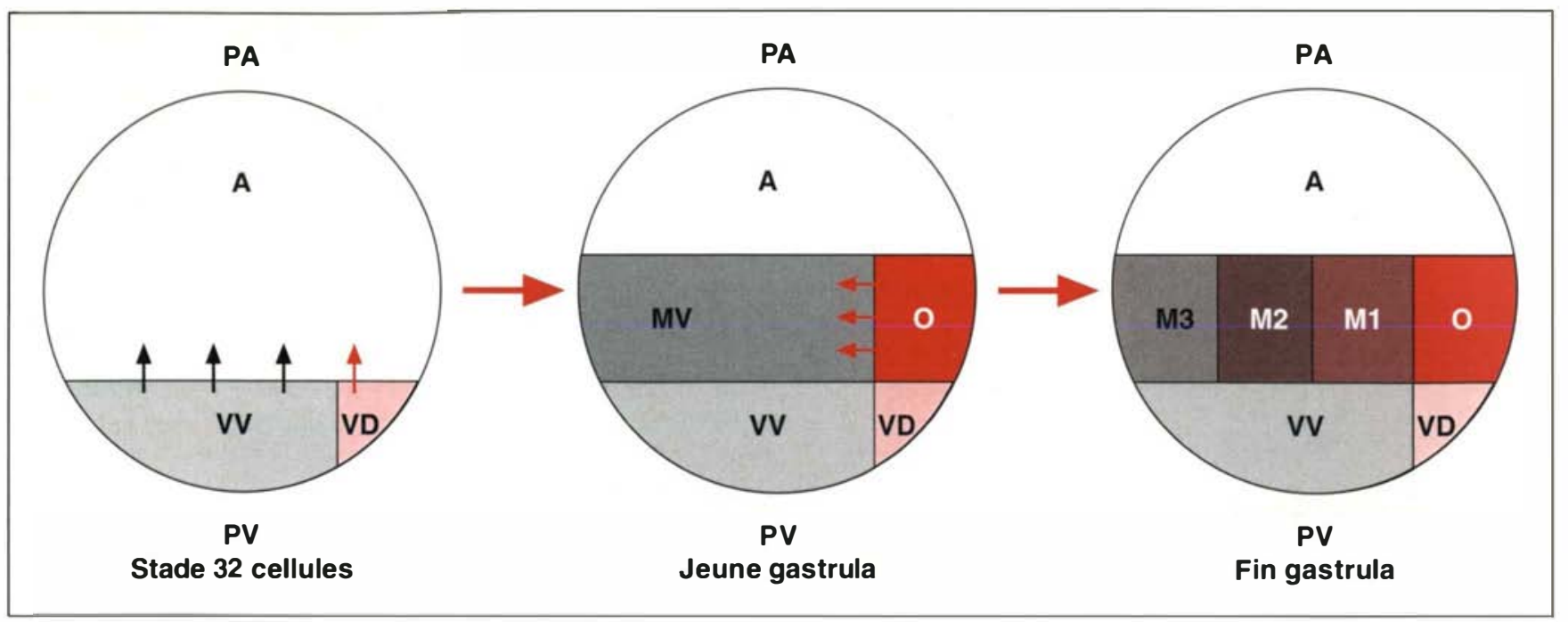

Figure 5. Modèle des trois signaux. Pendant la segmentation, deux signaux sont émis par l'hémisphère végétatif : un signal végétatif dorsal (VD) et un signal végétatif ventral (VV). Le signal végétatif dorsal induit l'organisateur de Spemann (O), alors que le signal végétatif ventral induit le mésoderme ventral (MV) dans la zone marginale. Au cours de la gastrulation, un troisième signal est émis par l'organisateur. II "dorsalise " le mésoderme ventral adjacent (M1 : mésoderme dorsolatéral; 12 : mésoderme ventrolatéral; M3 mésoderme ventral). $A$ : hémisphère animal ; PA : pôle animal ; PV : pôle végétatif. (D’après [16].)

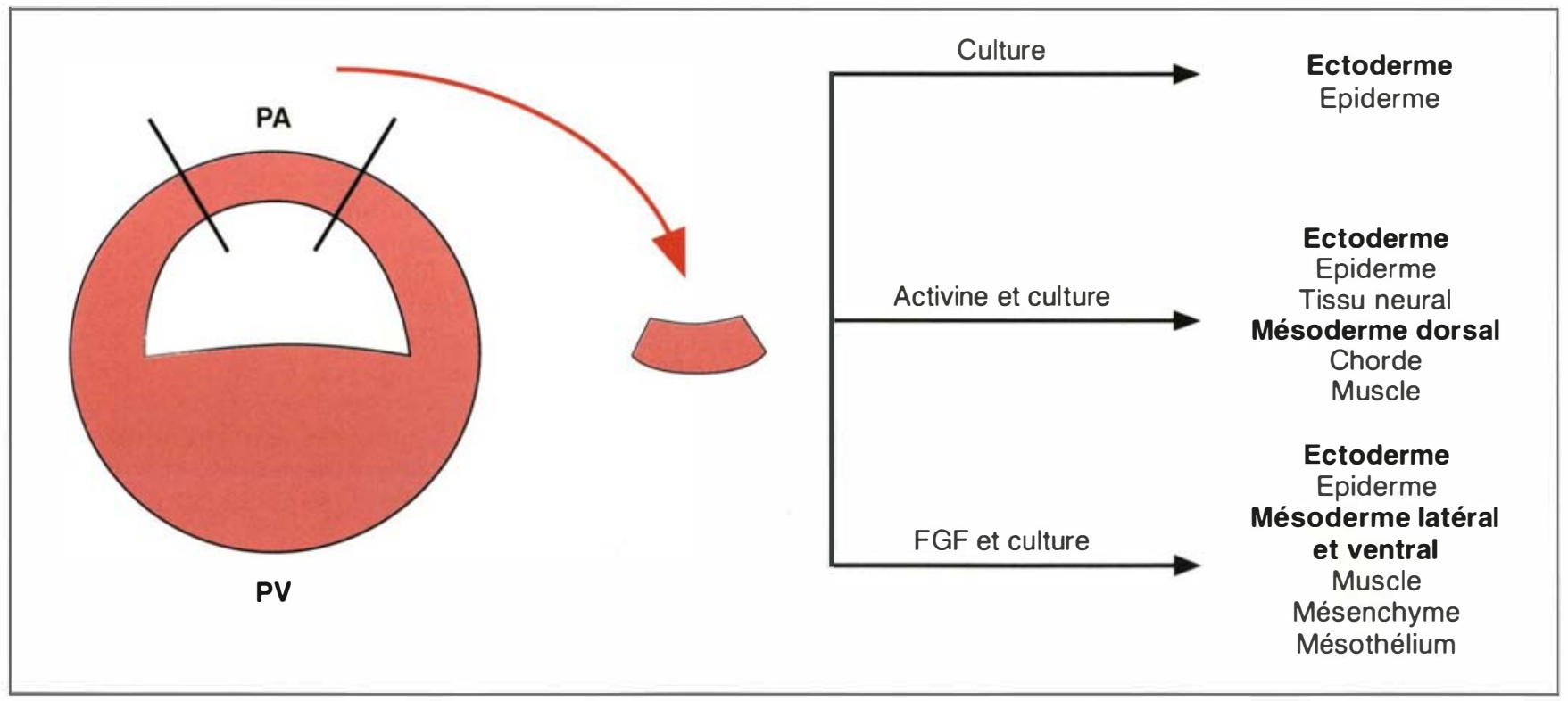

Figure 6. Induction de mésoderme dans la calotte animale ectodermique par les facteurs de croissance. La calotte animale ectodermique isolée au stade blastula et mise en culture se différencie en épiderme. Lorsqu'elle est incubée avec des facteurs de croissance FGF ou activine, elle se différencie en structures mésodermiques. Le FGF induit du mésoderme latéral et ventral (muscle, mésenchyme et mésothélium). L'activine induit du mésoderme dorsal (chorde, muscle) ou latéral (muscle, mésenchyme). PA : pôle animal ; PV : pôle végétatif. 


\section{RÉFÉRENCES}

36. Smith WC, Harland RM. Expression cloning of noggin, a new dorsalizing factor localized in the Spemann organizer in Xenopus embryos. Cell 1992 : 70 : 829-40.

37. Condamine $H$. L'organisation de l'embryon d'amphibien. médecine/sciences $1992 ; 8$ : 483-6.

38. Nusse R, Varmus HE. Wnt genes. Cell $1992 ; 69: 1073-87$.

39. McMahon AP, Moon RT. Ectopic expression of the proto-oncogene int-1 in Xenopus embryos leads to duplication of the embryonic axis. Cell $1989 ; 58$ : 1075-84.

40. Christian JL, Olson DJ, Moon RT. Xwnt8 modifies the character of mesoderm induced by bFGF in isolated Xenopus ectoderm. EMBO J $1992 ; 11: 33-41$.

41. Sokol S, Melton DA. Interaction of Wnt and activin in dorsal mesoderm induction in Xenopus. Dev Biol 1992 ; 154 : 348-55.

42. Moon RT, Campbell RM, Christian JL, McGrew LL, Shih J, Fraser S. Xwnt-5A : a maternal Wnt that affects morphogenetic movements after overexpression in embryos of Xenopus lavis. Development 1993 ; 119 : 97 111 .

43. Smith WC, Knecht AK, Wu M, Harland RM. Secreted noggin protein mimics the Spemann organizer in dorsalizing Xenopus mesoderm. Nature 1993 ; $361: 547-9$.

44. Joly JS, Cohen-Tanoudji M. L'unité de la gastrulation chez les vertébrés. médecine/sciences $1994 ; 10: 84-91$.

45. Smith JC, Price BMJ, Green JBA, Weigel D, Herrmann BJ. Expression of a Xenopus homolog of Brachyury $(T)$ is an immediate-early response to mesoderm induction. Cell $1991 ; 67$ : 79-87.

46. Cho KWY, Blumberg B, Steinbeisser $H$, De Robertis EM. Molecular nature of Spemann's organizer: the role of the Xenopus homeobox gene goosecoid. Cell $1991 ; 67: 1111-20$.

47. Taira M, Jamrich M, Good PJ, Dawid IB. The LIM domain-containing homeobox gene Xlim-1 is expressed specifically in the organizer region of Xenopus gastrula plus puissants in vitro [27]. Ce sont des homodimères de chaînes $\beta_{A}$ (activine A) ou $\beta_{B}$ (activine $B$ ). Les transcrits codant pour les polypeptides $\beta_{A}$ et $\beta_{B}$ des activines sont effectivement présents chez l'embryon de xénope, mais leurs expressions tardives (Tableau I) ne sont pas en accord avec le rôle attribué aux activines dans l'induction du mésoderme [28]. Il reste cependant qu'une activité de type activine $\mathrm{A}$ a pu être caractérisée à partir d'extraits protéiques d'œufs fécondés et de blastula de xénope. Plusieurs hypothèses peuvent rendre compte de ce paradoxe. En premier lieu, on peut évoquer la présence dans l'œuf d'une protéine non encore identifiée ayant une fonction de type activine. Une autre possibilité est que, malgré un très faible niveau d'expression, l'ARNm codant pour une forme d'activine puisse produire une quantité suffisante de protéine active au plan biologique. Enfin, les cellules folliculaires qui entourent les ovocytes renferment en abondance des transcrits $\beta_{\text {A }}$. L'activine sécrétée par les cellules folliculaires pourrait être captée et accumulée dans les ovocytes à la fin de l'ovogenèse [29, 30] Deux récepteurs maternels de l'activine, respectivement désignés, XAR1 et XAR7, ont été clonés chez le xénope. Ces récepteurs transmembranaires possèdent un domaine cytoplasmique à activité sérine/thréonine kinase impliqué dans la transduction du signal. Une mutation dominante négative produite par l'injection dans l'œuf fécondé d'ARNm exogène, spécifiant une forme du récepteur XARl délétée du domaine sérine/thréonine kinase, inhibe la formation du mésoderme chez l'embryon [31]. Cette expérience apporte un argument décisif en faveur de l'implication de l'activine dans les processus inducteurs du mésoderme in vivo.

L'effet de différentes concentrations d'activine A sur les cellules internes de calottes animales ectodermiques dissociées puis réagrégées de xénope a été récemment étudié $[32,33]$. Cette approche, conduite avec des marqueurs moléculaires de position, a permis de mettre en évidence la différenciation in vitro de cinq types de tissus; cela en fonction de la dose d'activine éprouvée. Les spécifi- cations épidermiques, de mésoderme postérieur et latéral, de muscle, de la chorde et de mésoderme possédant les propriétés de l'organisateur de Spemann, sont respectivement obtenues avec des concentrations croissantes d'activine. Il existe dans chaque cas une dose seuil spécifiant un type de tissu donné. De tels seuils ne sont pas mis en évidence dans les expériences similaires réalisées avec le FGF. Néanmoins, les doses seuils d'activine peuvent être modulées par le FGF.

\section{L'activité du centre de Nieuwkoop implique des inducteurs et des modificateurs de compétence}

L'identification des molécules pouvant être responsables de l'activité du centre de Nieuwkoop repose sur leur capacité à restaurer un axe normal chez un embryon traité par les UV (Tableau I). Cette expérience est réalisée en injectant les ARNm codant pour la molécule étudiée dans les blastomères végétatifs. $\mathrm{La}$ formation de l'axe embryonnaire ne suffit pas pour conclure que la molécule testée mime effectivement l'activité du centre de Nieuwkoop. Il doit, en outre, être établi que les cellules descendant des blastomères injectés ne participent pas aux structures mésodermiques de l'axe embryonnaire induit.

L'activine seule ne mime pas la totalité de l'activité du centre de Nieuwkoop. L'injection d'ARNm activine $B$ dans un blastomère végétatif d'un embryon traité par les UV restaure un axe embryonnaire. Cependant, cet axe est incomplet. Les structures antérieures céphaliques et la chorde sont le plus souvent absentes.

Récemment ont été découvertes des molécules qui, lorsqu'elles sont exprimées dans l'œuf de xénope traité aux UV, induisent un axe embryonnaire tout à fait complet. Il s'agit des produits des gènes de la famille Wnt, et du gène noggin [2, 34-37].

Les gènes Wnt comprennent le proto-oncogène murin wnt-1 (int-1) dont l'homologue chez la drosophile est le gène de polarité segmentaire wingless. Ils codent pour des pro- 


\begin{tabular}{|ccc|}
\hline \multicolumn{4}{c}{ Tableau I } \\
MOLÉCULES IMPLIQUÉES DANS LA FORMATION \\
DU CENTRE DE NIEUWKOOP
\end{tabular}

* MBT : midblastula transition, transition blastuléenne (voir texte).

téines sécrétées qui sont associées à la surface des cellules et à la matrice extracellulaire. Les protéines Wnt agissent comme des facteurs de croissance. Elles sont impliquées dans la communication cellulaire à courte distance $[37,38]$. Ia famille Wnt renferme au moins quatorze membres, dont six sont clonés chez le xénope (en particulier Xwnt-5, Xwnt-8 et Xwnt-11). L'intérêt porté aux gènes Wnt résulte de l'observation que l'injection, dans la partie ventrale de l'œuf, d'ARNm codant pour Wnt-1 ou pour Xwnt-8, entraîne la formation d'un second axe embryonnaire parfaitement constitué $[35,39]$. En outre l'injection de l'ARNm Xwnt- 8 dans les blastomères végétatifs d'un embryon au stade 32 cellules, issu d'un ouf irradié aux UV, restaure la formation d'un axe embryonnaire. Les traceurs de lignage montrent que les cellules qui dérivent des blastomères injectés constituent de l'endoderme, et ne conduit pas à la formation de dérivés mésodermiques. Xwnt-8 agit en synergie avec l'activine et/ou le FGFb. En potentialisant l'effet de ces inducteurs, il change le caractère du mésoderme. Ainsi, FGF qui induit la différenciation de mésoderme ventral dans la calotte animale de la blastula induit la formation de chorde lorsque ce tissu exprime Xwnt-8 $[40,41]$. D'où le terme de "modificateur de compétence" proposé pour désigner les facteurs qui, tels les Wnt, sont impliqués dans les inductions embryonnaires, sans être eux-mêmes des inducteurs.

Chez le xénope, deux Wnt, respectivement Xwnt-5 et Xwnt-11, sont d'expression maternelle. Cependant Xwnt-5 n'intervient pas dans l'induction du mésoderme et n'a pas d'effet discernable sur le développement embryonnaire avant le stade gastrula. Il serait un élément de régulation de l'adhérence cellulaire au cours de la gastrulation [42]. L'ARNm Xwnt11 , dont on a vu que son expression dans l'œuf fécondé était similaire à celle de $V g l$, est concentré dans la région dorsale de la blastula. L'injection d'ARNm Xwnt-11 dans l'œuf irradié par les UV' corrige partiellement la formation d'un axe embryonnaire. Il est constitué de mésoderme somitique et de tissu nerveux, mais entièrement dépourvu de chorde et de structures céphaliques antérieures [2]. Le rôle exact de Xwnt-11 dans les processus inducteurs du mésoderme demeure par conséquent une question ouverte.

Noggin qui n'appartient pas à la famille wnt peut, comme Xwnt-8, restaurer un axe embryonnaire dans l'œuf irradié aux UV. L'ARNm synthétique noggin, introduit au stade 32 cellules dans les blastomères végétatifs, soit d'un embryon irradié par les UV, soit d'un embryon normal, provoque l'édification d'un axe embryonnaire complet pourvu des structures céphaliques les plus antérieures. Ainsi noggin, comme Xwnt-8, mime l'activité du centre de Nieuwkoop: il induit l'organisateur de Spemann. En revanche, à la différence de $X w n t-8$ qui est exprimé après la MBT, noggin est d'expression maternelle, ce qui est en accord avec sa fonction de centre de Nieuwkoop. Chez l'œuf fécondé, l'ARNm noggin est distribué de 


\section{RÉFÉRENCES}

48. Dirksen ML, Jamrich M. A novel, activininducible, blastopore lip-specific gene of Xenopus lavis contains a fork head DNAbinding domain. Genes Dev 1992 ; 6 : 599 608.

49. Ruiz i Altaba A, Jessel TM. Pintallavis, a gene expressed in the organizer and midline cells of frog embryos : involvement in the development of the neural axis. Development 1992 ; 116: 81-93.

50. von Dassow G, Schmidt JE, Kimelman D. Induction of the Xenopus organizer: expression and regulation of Xnot, a novel FGF and activin-regulated homeobox gene. Genes Dev 1993 ; 7 : 355-66.

51. Camus A, Babinet C. brachyury, un gène essentiel pour la gastrulation et la formation du mésoderme chez les vertébrés. médecine/sciences $1993 ; 9: 1118$ 21.

52. Halpern ME, Ho RK, Walker C, Kimmel $\mathrm{CB}$. Induction of muscle pionneers and floor plate is distinguished by the zebrafish no tailmutation. Cell 1993 ; 75 : 99 111.

53. Cunliffe V, Smith JC. Ectopic mesoderm formation in Xenopus embryos caused by widespread expression of a Brachyury homolog. Nature $1992 ; 358: 427-30$.

54. Amaya E, Stein PA, Musci TJ, Kirschner MW. FGF signalling in the early spe-cification of mesoderm in Xenopus. Development $1993 ; 118$ : 477-87.

55. Niehrs C, Keller R, Cho KWY, De Robertis EM. The homeobox gene goosecoid controls cell migration in Xenopus embryos. Cell $1993 ; 72: 491-503$.

56. Niehrs C, Steinbeisser H, De Robertis EM. Mesodermal patterning by a gradient of the vertebrate homeobox gene goosecoid. Science $1994 ; 263$ : 817-20.

57. Christian JL, Moon RT. Interactions between Xwnt-8 and Spemann organizer signaling pathways generate dorsoventral pattern in the embryonic mesoderm of Xenopus. Genes Dev 1993 ; 7 : 13-28.

58. Zhou X, Sasaki H, Lowe L, Hogan BLM, Kuehn MR. nodal is a novel TGF- 3 -like gene expressed in the mouse node during manière uniforme. Chez la blastula, et plus particulièrement au cours de la gastrulation, noggin est situé dans la zone marginale et se concentre dans la région dorsale [36, 43]. Comme Xwnt-8, noggin est capable d'agir en synergie avec les inducteurs du mésoderme, tel le facteur de croissance FGFb. Il apparaît ainsi que l'activité du centre de Nieuwkoop résulterait d'une combinatoire où interviendraient des facteurs de croissance inducteurs, tels l'activine et le FGF, ainsi que des facteurs de signalisation "modificateurs", tels noggin et des membres de la famille Wnt.

\section{Les inducteurs du mésoderme et les " modificateurs" règlent l'expression $d$ 'au moins six facteurs de transcription}

On peut s'attendre à ce que la formation du mésoderme dans la zone marginale, en réponse aux signaux inducteurs émis par l'hémisphère végétatif, requière l'intervention de nombreux gènes et, par conséquent, l'expression spécifique de plusieurs facteurs de transcription. La caractérisation de ces gènes, en particulier ceux contrôlant l'activité de l'organisateur de Spemann, est au centre des recherches menées actuellement [44]. Au moins six gènes codant pour des facteurs de transcription sont fortement exprimés dans la zone marginale de la jeune gastrula. Tous sont transcrits après la MBT, en réponse à l'activine et en absence de synthèse protéique. L'un, XBra, est l'homologue du gène brachyury (T) de la souris. Il est exprimé dans l'ensemble de la zone marginale au stade gastrula [45]. L'expression des cinq autres gènes est restreinte à la zone marginale dorsale, c'est-à-dire la région de l'organisateur de Spemann. Les traceurs de lignage cellulaire montrent que les cellules qui expriment ces gènes constituent les structures mésodermiques de l'axe embryonnaire. Il s'agit des gènes goosecoid [46], Xlim-1 [47], X FKH-1 [48], Pintallavis [49], Xnot [50]. Ce sont tous des gènes à homéoboîte.

Il est actuellement établi que $b r a$ chyury joue un rôle très important dans la formation du mésoderme chez les vertébrés. Chez la souris, la perte de fonction de ce gène chez les mutants homozygotes $\mathrm{T} / \mathrm{T}$ perturbe la formation de la ligne primitive et entraîne un déficit important dans la formation du mésoderme [51]. Chez le poisson zèbre, la mutation de l'homologue de brachyu$r y$, no tail ( $n t l)$ produit des embryons sans chorde ni région caudale et dont les somites du tronc sont anormaux [52]. Chez le xénope, l'injection d'ARN synthétique $\mathrm{XBra}$ provoque la formation de mésenchyme, de mésothélium et de petites quantités de muscle dans la calotte ectodermique [53]. Ces résultats montrent que XBra est suffisant pour convertir l'ectoderme en mésoderme ventral. L'expression de la mutation dominante négative du récepteur FGF inhibe celle de XBra indiquant que $\mathrm{XBr}$ a est également contrôlé par FGF [54].

Le goosecoid joue un rôle majeur dans l'acquisition des propriétés de l'organisateur de Spemann. L'injection d'ARNm goosecoid dans les deux blastomères ventraux de la région équatoriale d'un embryon au stade 32 cellules induit la formation d'un axe embryonnaire surnuméraire. L'utilisation des traceurs de lignage montre que les cellules des blastomères injectés participent aux structures mésodermiques dorsales de l'axe induit. Elles peuvent recruter dans ces structures les cellules provenant des autres blastomères ventraux [55]. Xnot possède la particularité d'être non seulement contrôlé par l'activine, mais aussi par FGF. La mutation dominante du récepteur FGF provoque ainsi l'inhibition de l'expression de Xnot dans l'organisateur de Spemann, alors qu'elle n'a aucun effet sur celle de goosecoid [54]. La surexpression de Xnot dans la région dorsale de l'embryon provoque une hypertrophie de la chorde.

Une autre observation importante est qu'au début de la gastrulation les cinq gènes à homéoboîte exprimés dans l'organisateur de Spemann le sont en des régions différentes. Les transcrits goosecoid et XLim-1 sont situés dans le mésoderme préchordal qui contribue aux formations mésodermiques les plus antérieures. $X$ FKH-1 et Pintallavis sont initialement exprimés dans les régions antérieures et moyennes de l'organisa- 
teur de Spemann, puis plus fortement dans les cellules du chordomésoderme qui constituent la chorde. Enfin, Xnot a son domaine d'expression restreint aux cellules qui donnent la chorde et la plaque du plancher neural $[50,54]$.

Il faut souligner enfin que dans la zone marginale de la jeune gastrula, les ARNm goosecoid sont répartis selon un gradient, avec un maximum de concentration dans la région la plus dorsale. Ainsi, selon qu'elles expriment une quantité élevée, moyenne ou faible de goosecoid, les cellules du mésoderme constituent respectivement de la chorde, du muscle ou du pronephros. Ces éléments renforcent le rôle clé attribué à goosecoid dans la détermination du patron du mésoderme. Au début de la gastrulation, le gradient d'expression de goosecoid traduit l'information de position délivrée précédemment par le centre de Nieuwkoop [56].

L'ensemble de ces données montre que les inducteurs (activine, FGF) contrôlent l'expression d'un gène impliqué dans la conversion des cellules ectodermiques en mésoderme, $X B r a$, dans les cellules de la zone marginale de la gastrula. L'action synergique de ces inducteurs et des "modificateurs" (Wnt, noggin) règle de manière différentielle l'expression des gènes à homéoboîte dans les cellules du mésoderme dorsal qui constituent l'organisateur de Spemann. Celles qui dépendent uniquement de la signalisation relayée par l'activine expriment goosecoid. Elles représentent le mésoderme préchordal. Celles qui requièrent à la fois l'activine et le FGF expriment Xnot. Elles contribuent à la formation de la chorde et des somites. Ainsi, les recherches actuelles mettent en valeur le rôle joué par les gènes à homéoboîte dans la formation de l'organisateur de Spemann, tout en laissant ouverte la question des gènes cibles.

\section{La régionalisation du mésoderme : les apports de l'analyse moléculaire}

Comme nous l'avons vu, les expériences de microchirurgie embryonnaire montrent que l'organisateur de
Spemann a un effet "dorsalisant " sur le mésoderme ventral. De fait, c'est au cours de la gastrulation que la régionalisation dorsoventrale du mésoderme est accomplie. Quelles sont les molécules qui relaient les interactions inductrices entre les cellules de l'organisateur de Spemann et celles de la zone marginale latérale ? On peut postuler que les cibles des protéines Goosecoid, XLim-1, Pintallavis, $\mathrm{X}$ FKH-l et Xnot règlent la production de facteurs diffusibles ou associés à la surface des cellules impliquées dans ces interactions.

Xwnt-8, dont l'expression avant la MBT peut mimer l'activité du centre de Nieuwkoop, joue très vraisemblablement un rôle clé au cours de la gastrulation. A ce moment, Xwnt-8 est uniquement exprimé dans les régions ventrale et latérale. Les cellules de la zone marginale dorsale n'expriment pas Xwnt-8. Ce sont elles qui constituent l'organisateur de Spemann. Elles donnent le mésenchyme céphalique ainsi que la partie rostrale de la chorde. Une expression ectopique de Xwnt-8 ciblée dans l'organisateur de Spemann inhibe totalement cette différenciation : l'axe embryonnaire ne contiendra ni mésenchyme céphalique, ni chorde, mais des formations musculaires [57]. Cela conduit à proposer que goosecoid, dont l'expression est activée avant celle de Xwnt-8, puisse régler négativement celle de Xwnt- 8 dans les cellules de l'organisateur de Spemann, c'est-àdire dans celles qui sont à l'origine du facteur dorsalisant. Dans les cellules du mésoderme des zones ventrale et latérales de la gastrula, le signal engendré par Xwnt-8 aurait pour fonction d'atténuer leur réponse, de les rendre moins compétentes, au facteur dorsalisant.

La protéine noggin est capable de produire in vitro un effet dorsalisant sur le mésoderme ventral de la gastula. Ce rôle comparable à celui exercé in vivo par l'organisateur de Spemann est en accord avec le domaine d'expression de noggin qui au début de la gastrulation est restreint à la zone marginale dorsale. Ensuite, au cours de la gastrulation, l'expression de noggin suit l'évolution du mésoderme dorsal. Par ailleurs, lorsqu'on provoque l'expression de noggin après la MBT, chez un embryon irradié aux UV, il se forme un axe embryonnaire avec des structures mésodermiques dorsales. Par conséquent, le rôle de noggin diffère au cours du développement. Par son expression maternelle, noggin est, pendant que se déroulent les premiers cycles cellulaires, un modificateur impliqué dans l'activité du centre de Nieuwkoop. Plus tard, chez la gastrula, noggin, qui est exprimé dans l'organisateur de Spemann, joue le rôle d'un facteur "dorsalisant " intervenant dans la régionalisation dorsoventrale $\mathrm{du}$ mésoderme. La régulation de l'expression zygotique de noggin par les gènes à homéoboîte exprimés dans l'organisateur de Spemann se trouve posée.

Le gène nodal, récemment identifié chez la souris, code pour un nouveau membre de la famille des facteurs de croissance TGF $\beta$. La perte de fonction de ce gène chez des mutants homozygotes provoque l'absence complète de mésoderme. Les transcrits de nodal sont détectés pendant la gastrulation au niveau $\mathrm{du}$ nœud, qui est le centre organisateur chez l'embryon de souris, homologue de l'organisateur de Spemann des amphibiens. Nodal est faiblement exprimé avant la gastrulation, et il est possible qu'il intervienne dans les premières étapes de la formation du mésoderme. Son niveau d'expression élevé pendant la gastrulation, ainsi que la localisation de ses transcrits, suggèrent que nodal joue également un rôle dans les interactions au voisinage du centre organisateur [58]. Des gènes apparentés à nodal viennent d'être isolés chez le xénope. Leur expression, ou celle de nodal de souris, dans la calotte ectodermique provoque la formation de mésoderme dorsal. La fonction exacte de nodal dans la formation et dans la régionalisation du mésoderme chez les vertébrés devrait être clarifiée dans un avenir très proche par les études conjointes effectuées chez le xénope et la souris.

\section{Conclusion}

La conjonction des données apportées par l'embryologie expérimentale et la biologie moléculaire a permis en quelques années de préciser les mécanismes qui sous-tendent l'in- 


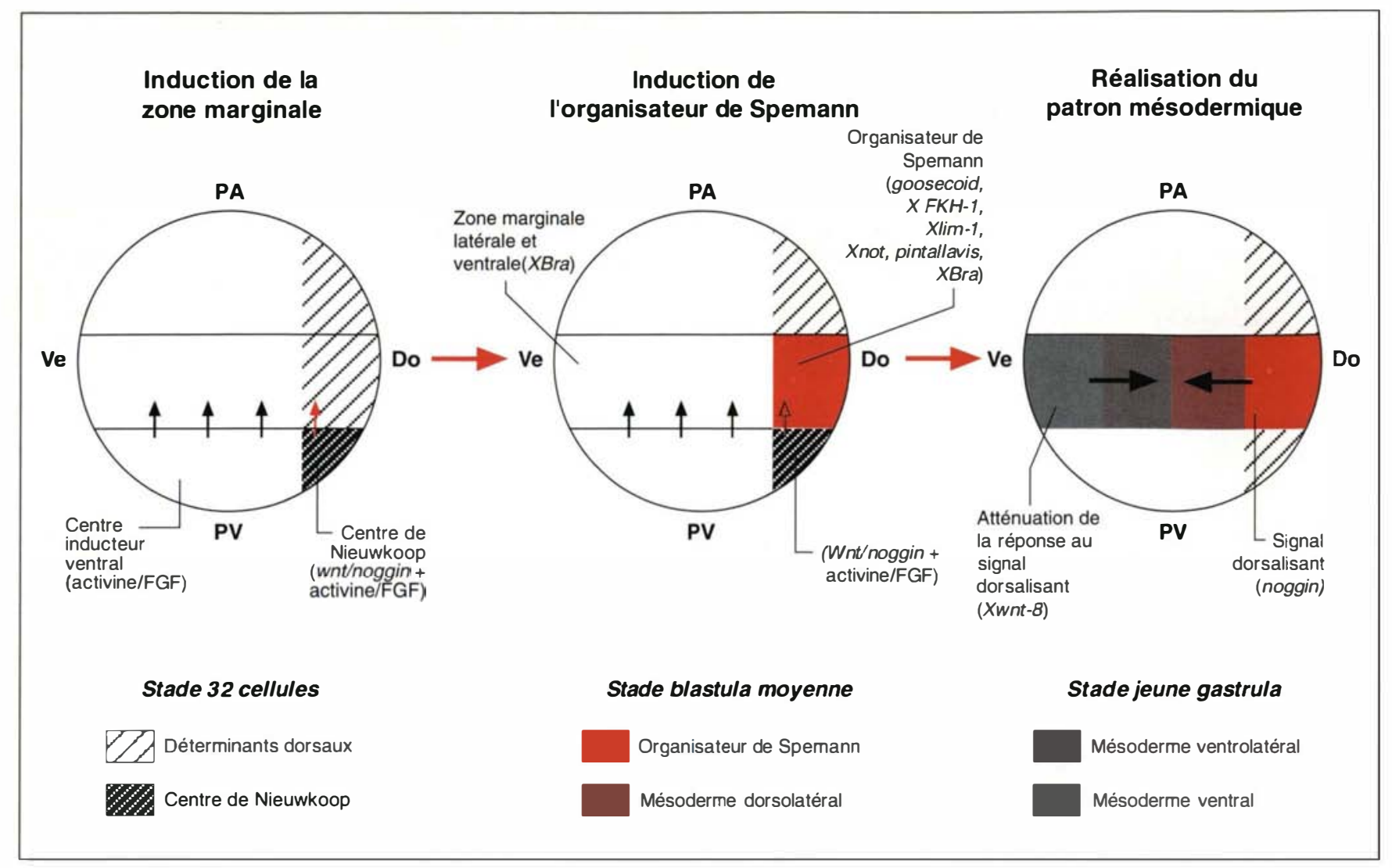

Figure 7. Modèle d'interprétation moléculaire de l'induction du mésoderme. Dès le stade 32 cellules, des signaux émis par l'hémisphère végétatif induisent des cellules de l'hémisphère animal en mésoderme. Le centre inducteur végétatif dorsal ou centre de Nieuwkoop induit du mésoderme dorsal. Les blastomères végétatifs ventraux et latéraux induisent les cellules des régions ventrales et latérales de l'hémisphère animal en mésoderme ventral. Les facteurs de croissance activine et FGF sont impliqués. Ventralement et latéralement, ils induisent la formation de mésoderme ventral. Dorsalement, en synergie avec les facteurs de signalisation Wnt et/ou noggin, ils induisent le mésoderme dorsal. Ce dernier n'est totalement induit qu'au stade blastula âgée où il constitue l'organisateur de Spemann. Le mésoderme induit occupe approximativement la région équatoriale ou zone marginale de la jeune gastrula. Cette région correspond au domaine d'expression de XBra. L'activité de l'organisateur de Spemann implique l'expression d'au moins cinq gènes à homéoboîte : goosecoid, X FKH-1, Xlim-1, Xnot et pintallavis. La régionalisation du mésoderme selon l'axe dorsoventral est accomplie au cours de la gastrulation. Elle résulte de I'action combinée de signaux " dorsalisants", tels noggin, et de facteurs de signalisation, comme Xwnt-8. Ces derniers modifient la compétence, c'est-à-dire l'aptitude des régions latérales et ventrale de la zone marginale à répondre aux signaux dorsalisants. Do : région dorsale; $P A$ : pôle animal ; PV : pôle végétatif; Ve : région ventrale.

plein essor, le xénope demeure un modèle privilégié. Les interactions cellulaires qui président à la formation du mésoderme chez le xénope sont celles qui, à ce jour, sont les mieux connues parmi tous les vertébrés. Il sera très intéressant d'étendre ces données aux autres vertébrés, en particulier à ceux qui, comme le poisson-zèbre ou la souris, autorisent une dissection génétique des processus en cause

\section{TIRÉS A PART}

J.-C. Boucaut. ciation du mésoderme devraient être mieux définies. Dans ce domaine en duction du mésoderme chez le xénope (figure 7). L'approche moléla nature exacter de compétence ainsi que celle de de transduction impliquées et les cascades de régulation qui contrôlent les différentes voies de différen- 


\section{Summary}

Induction of the mesoderm

Mesodermal induction is one of the most important events that lead to the establishment of the primary body plan in vertebrate embryos. Our knowledge of this process is based on concepts which have arisen essentially from experimental embryological studies on amphibian embryos. Our understanding of inductive processes and mesoderm patterning at the molecular level has considerably progressed in the last few years. There is increasing evidence that induction of the dorsal mesoderm of the early gastrula (Spemann organizer) results from the combined action of growth factors such as FGF and activin together with competence modifyers such as Wnt or noggin. The activity of the Spemann organizer requires the expression of several homeobox genes among which goosecoid most probably plays a crucial role. These data have been obtained in Xenopus embryos but investigations should certainly be extended in the near future to higher vertebrates, particularly to mammals where they are still very incomplete.

\section{ERRATUM}

La démence sénile en France $\left(\mathrm{m} / \mathrm{s} n^{\circ}\right.$ 6-7, vol. 10, juin-juillet 1994, pages 680-6).

A la suite d'une erreur d'impression, la méta-analyse qui a servi de base aux projections de la prévalence de la démence en France a été attribuée à tort à Jorm et Korten (1988). Cette méta-analyse, et les modèles qui en ont résulté sont le travail de l'auteur: Ritchie et al. Int J Epidemiol 1992 ; 21 : 763-9 ([6] dans le texte). C'est également à cette référence que renvoie la mention "Modèles de Ritchie et al. " dans les Tableaux et non pas à la référence [26] comme imprimé. 